\title{
Depression, the Family, and Family Therapy
}

\author{
James C. Coyne and Suzanne Fechner-Bates ${ }^{\star}$
}

\begin{abstract}
The potential contribution of family therapists to the treatment of depression remains underdeveloped. Family therapists need to articulate how changes in family functioning might benefit depressed persons, as well as how other problems in the families of depressed persons tend to go unrecognised. Furthermore, family therapists need to be alert to how undetected depression in adults and children may interfere with their ability to meet their goals with families who seek therapy for other persons. This article provides family therapists with (1) an overview of the nature and experience of depression; (2) an introduction to antidepressant medication; (3) a summary of research findings relating depression to its family context and (4) a brief overview of developments in the marital and family treatment of depression.
\end{abstract}

Clinical depression tends to be a marker for families with a full range of other difficulties. The marital conflict, parenting difficulties, adjustment problems of offspring, and more generalised family dysfunction associated with depression in an adult would all seem to warrant a role for marital and family therapy in its treatment. There is also strong, even if largely circumstantial, evidence that intervention with these relationships should be of direct benefit to the depressed person. Unfortunately, the potential contribution of family therapists to the treatment of depression remains largely ignored.

By promoting an awareness of the family context of depression, family therapists could counter the reductionistic view that depression is merely a biological illness to be treated exclusively with medication or electroconvulsive therapy (ECT). Yet, in general, family therapists tend to be ill-informed about advances in the study and treatment of depression from a biological perspective. Moreover, most family therapists need to develop a better knowledge of the complex relationship between depression and marital and family functioning before they could engage other mental health professionals in a dialogue about what they have to offer and how this approach is to be seen as either an alternative or a supplement to more established treatments. Family therapists must become more prepared if they are to take an active role in assuring that depressed persons and their families get the best possible treatment and that their full range of problems is addressed.

This article has four related purposes. It is intended to provide family therapists with firstly, an overview of the nature and experience of depression; secondly, an introduction to antidepressant medication and its impli- cations for family therapists; thirdly, a sense of the variety of research findings relating depression to its family context; and fourthly, a brief overview of marital and family approaches to depression, which remain in an early stage of development. While this article is necessarily brief, we cite literature that can be seen as a useful starting point for readers interested in pursuing these issues in greater depth.

\section{THE NATURE AND EXPERIENCE OF DEPRESSION}

Formally speaking, a diagnosis of Major Depression requires evidence of at least one primary symptom and at least four associated symptoms lasting nearly every day for at least two weeks (American Psychiatric Association, 1987). Depressed mood and a distinct loss of interest of pleasure in most or all activities (anhedonia) count as primary symptoms. The secondary symptoms are 1) appetite disturbance or weight change, 2) sleep disturbance, 3) psychomotor agitation or retardation, 4) fatigue or loss of energy, 5) feelings of worthlessness or guilt, 6) diminished concentration or decision making ability, and 7) thoughts of death or suicide.

There are considerable differences among depressed people, and while it is useful for some purposes to talk about endogenous versus nonendogenous depressions, this distinction must now be understood under new terms. The old notion was that some depressions are basically biological in nature and in need of biological treatment, while others, reactive depressions, are understandable

\footnotetext{
*University of Michigan Medical School, Ann Arbor, Michigan, U.S.A 48109-0708.
} 
responses to stressful life circumstances and thus amenable to some form of psychotherapy. This is an oversimplification. Some symptoms do predict a greater likelihood of responding to antidepressant medication. These symptoms are: (1) a lack of reactivity of mood to changes in life circumstances during an episode (Fowles \& Gershon, 1979), (2) anhedonia, (3) psychomotor retardation, (4) feeling worse in the morning as opposed to the evening, (5) early morning awakening and (6) diminished appetite (Clayton \& Barrett, 1983). These symptoms may also interfere with depressed persons becoming engaged in therapy, their following through with therapeutic task assignments, or their deriving any sense of benefit from what progress the family makes. Yet these symptoms are at best weakly associated with the presence or absence of precipitating stress (Dolan et al., 1985). Indeed, depression in the complete absence of life stress is actually relatively rare (van Praag, 1982). Consequently, a particular patterning of symptoms, rather than the absence of stress, is now taken to define endogenous depression and the term "reactive depression" has been discarded.

A family therapist encountering a depressed person with significant endogenous symptoms should be alert to a lack of progress and be willing to consider a consultation or referral for medication if this is the case. Yet endogenous symptoms are not an indication that the depressed person's marriage and family life can be ignored. "There is currently no evidence to support strict adherence to either a psychotherapeutic or pharmacological model of treating outpatient depression" (Beckman \& Leber, 1985, page 328). It is our belief that many depressed persons and their families benefit from a combined approach, in which the family therapist takes advantage of the increased energy, better concentration and reactivity of mood derived from the depressed person's treatment with antidepressant medication to curtail hostile, critical responses from family members. In turn, the improvement in the family atmosphere may actually promote the depressed person's response to the medication.

Family therapists who work with depressed persons need to be sensitive to how badly they feel. Persons who have suffered a clinical depression readily distinguish it from periods when they have simply been sad, unhappy, or grieving. Depressed persons describe themselves as feeling slowed down, living in a fog, depleted of energy, inefficient, disorganised, and easily tired. Comparative studies have found that depressed persons spend more days in bed and have fewer days functioning at full capacity than persons suffering from such chronic illnesses as hypertension, arthritis and diabetes (Wells et al., 1989).

Depressed persons may have trouble reciprocating pleasantries, showing enthusiasms or affection, or simply being attentive enough to participate in a conversation. They may find it difficult to express how badly they are feeling and may simply withdraw rather than face the lack of sympathy, useless advice, and outright hostility that they receive from others. Many changes in them are subtle and confusing to family members, thereby perpetuating misunderstandings and conflict over their seemingly wilful ineptness or laziness. Family members may believe that the depressed person is just not trying hard enough, or they may take personally the depressed member's irritability or inability to muster up a pleasant appearance.

Understandably, the depressed person's relationships and family are distressed. Conflict and inadequacies in these relationships are likely to have played a role in the person having become depressed. Yet it is also difficult for depressed persons to maintain their relationships, and life with a depressed person can prove burdensome (Coyne $e t$ $a l ., 1987)$. Family therapists need to think systemically and contextually in drawing links between depression and the patterning of family relationships.

\section{TREATMENT APPROACHES}

\section{Antidepressant Medications}

Following the introduction of Prozac (fluoxetine) in the United States, family therapists found themselves fielding questions from clients about antidepressant medication and even direct requests for prescriptions or referrals to physicians. Many therapists reacted with undue alarm. Fishman lamented that "Family therapists risk being coopted back into a way of thinking that we revolted against four decades ago. I'm afraid we may return to treating symptoms and not trying to understand people's lives in a broader context"' (quoted in Markowitz, 1991, page 30). Similarly, Yapko argued that "Like a band-aid on a broken leg, pills do nothing to address the underlying malaise" (quoted in Markowitz, 1991, page 31). Perhaps what has been most disappointing about the ensuing controversy is that so little attention is paid to the literature concerning the relative effectiveness of antidepressant medication.

In a highly publicised case in the United States, a psychoanalyst has now been successfully sued for malpractice because he did not recommend medication to a depressed man who was not benefiting from analysis. However family therapists may feel about them, antidepressants can provide highly efficacious treatment for most depressed persons, with about $60-75 \%$ of patients with major depression showing a positive response. The various antidepressants are on the average about equal in effectiveness, although individual depressed persons will differ in their responsiveness to a particular drug. The choice of the best antidepressant is often dependent upon minimising the side effects that are produced and the person's ability to tolerate them. Tricyclics are the largest class of antidepressants and include amitriptyline (Elavil), imipramine (Tofranil), desimpramine (Norpramin) and nortriptyline (Pamelor). Another class is monoxidase inhibitors (MAOIs), including phenelzine (Nardil) and tranylcypromine (Parnate). Both of these types of antidepressants affect neurotransmitter activity causing increased catecholamine activity in the brain, although the effect is achieved through varied mechanisms.

The newest type of antidepressants, heterocyclics, includes fluoxetine (Prozac). Fluoxetine is an inhibitor of serotonin re-uptake in the brain. It has expanded medication treatment options for persons who were unresponsive to other medications. It is not as likely as 
other antidepressants to produce weight gain, and it has reduced toxicity risks and therefore carries decreased risk of suicide by overdose (Bender, 1990). But despite all the attention it has received, it is not considered a front line drug. It is not tolerated by many depressed persons, and experienced psychiatrists tend to utilise tricyclics first.

There are limits to the effectiveness of antidepressants and their acceptability to depressed persons. They are not a panacea, nor are they "happy pills" or "uppers". On the other hand, they are not addictive: nondepressed persons feel worse, not euphoric, after taking antidepressants. Antidepressants take at least two weeks to reach therapeutic dose, and up to four weeks to affect symptoms (Bender, 1990). In the interim, the depressed person may feel somewhat worse rather than better. Some depressed persons cannot tolerate the side effects of antidepressants. Weight gain, dizziness, sexual dysfunction, increased anxiety and drowsiness are among the reasons most cited for stopping antidepressant medication. An adjustment in dosage or a change in antidepressants may eliminate many of these problems, but some patients still cannot tolerate the level of medication needed for a therapeutic response. There is also the risk of suicide: a week's supply of tricyclics is sufficient.

Despite the promise of medication treatments, some depressed persons fail to respond altogether or the problems associated with their depression require psychotherapy (Keller \& Shapiro, 1982; Keller et al., 1984). Antidepressants do not solve interpersonal problems, and family relationships often remain hostile, inhibited and dependent following a depressive episode (Glick, Burti, Minakawa, Machara \& Sacks, 1991). On the other hand, by improving troublesome symptoms like disrupted sleep, low energy level and depressed mood, medication may free depressed persons to tackle their other problems (Morgan, 1988).

\section{Individual Psychotherapy}

If antidepressant medication is effective, what role is there for therapy? The United States National Institute of Mental Health undertook a large scale collaborative outcome study and found that two brief therapies, cognitive and interpersonal, were as effective as standard treatment with medication (Elkin et al., 1989). Only with severely depressed persons was there a clear advantage to medication. All three treatments were more effective than placebo, but all failed for a substantial minority of depressed persons.

It would seem then that some sort of matching of depressed persons' characteristics to treatment type, medication or therapy would be in order. Unfortunately, proven treatment selection criteria are largely lacking, and the evidence is mixed as to whether a combination of medication and psychotherapy is most effective (Beckman \& Leber, 1985; Blackburn et al., 1981; Glick et al., 1991; Murphy, Simons, Wetzel \& Lustman 1984; Rounsaville et al., 1981; Thase et al., 1984). Our reading of the literature led us to conclude that (1) in the absence of clear-cut guidelines, professionals need to be flexible and consider their alternatives when either medication or psychotherapy is proving insufficient; (2) there is no evidence that antidepressant medication interferes with psychotherapy; (3) for mild or moderate depression, a combination of treatments is probably no better on average than either psychotherapy or medication if one focuses only on the depressed persons' symptoms; (4) the kinds of marital and family problems that are often associated with depression do not show substantial improvement with medication alone; (5) more severely depressed persons are particularly likely to have serious family problems and combined treatment may be in order.

Cognitive and interpersonal therapies differ in their rationales, but they are both brief and goal-oriented and emphasise constructive changes in behaviour, rather than the attainment of insight. They are also individual therapies. Why were marital and family therapy not entered into this comparison? They failed to meet two criteria for inclusion (Coyne, 1991): they lacked both documentation of their effectiveness for depression and systemisation in the form of treatment manuals. Family therapists' enthusiasm and dramatic case examples were not enough.

\section{Marital and Family Therapy for Depression: Promises, Promises}

There is now some limited evidence that marital therapy can be effective for depression, by itself and in combination with other approaches (Friedman, 1975; O'Leary \& Beach, 1990; Jacobson et al., 1991; Foley et al., 1989). A treatment manual for the behavioural marital treatment of depression has also been published (Beach, Sandeen \& O'Leary, 1990). There have been some preliminary efforts to develop inpatient family interventions for affective disorders (Clarkin et al., 1990) and behavioural family interventions for bipolar patients receiving lithium (Miklowitz \& Goldstein, 1990). Yet, at the present time, the main arguments for marital and family therapy for depression must be made with circumstantial evidence, not outcome data of the kind available for cognitive and interpersonal therapy.

The two main arguments are:

(1) Interpersonal therapy has been shown to be effective and it seeks to effect changes in depressed persons' involvement in their relationships. It would seem more efficient and effective to involve spouses and family members directly in treatment rather than work through the depressed person alone. Foley et al. (1989) have produced some evidence that this may be the case.

(2) Marital and family problems accompany depression, and there is evidence that they reduce response to conventional treatment (Rousanville et $a l ., 1980$ ) and make relapse more likely (Hooley \& Teasdale, 1989).

At the present time, the strongest argument for marital and family therapy for depression is this rich set of links between depression and the family. Therapists would do well to familiarise themselves with these links. 


\section{DEPRESSION IN FAMILIES}

Depression tends to run in families (Coyne, Burchill \& Stiles, 1991). Heredity undoubtedly plays a role, but its influence has been overestimated. A recent large-scale study of twins found the heritability of both severe and moderate depression is modest, less than for hypertension, schizophrenia or bipolar disorder. The heritability of depression was only about the same as for peptic ulcers and coronary artery disease, conditions for which the contribution of the environment is well established (Kendler et al., 1992). Another well-designed twin study found support for a genetic contribution to depression, but that the family environment made a higher contribution in predicting which twins became severely depressed and in need of hospitalisation (McGuffin, Katz \& Rutherford, 1991). The authors concluded that "both genetic factors and shared family environment make substantial and significant contributions to the familiarity of depression"' (McGuffin et al., 1991, page 329).

\section{Family Functioning}

Families with a depressed member are characterised by poor problem solving (Hops, Biglan, Sherman et al., 1987), high tension (Hinchliffe, Hooper, Roberts et al., 1975), frequent arguments and high friction (Weissman \& Paykel, 1974), poor communication and poor general functioning (Keitner \& Miller, 1990). In fact, families with a depressed member consistently show more maladjustment than the families of persons with alcohol dependence, schizophrenia or bipolar disorder (Crowther, 1985; Miller et al., 1986).

Some of the connections between family life and depression are not well understood. For instance, simply being married predicts slower recovery from depression (George et al., 1989) and reduced response to antidepressant medication (Keller et al., 1984). Depressed persons often have hostile relationships with family members, and the number of hostile critical comments that family members make in interviews at the time of a depressed person's hospitalisation is an excellent predictor of subsequent relapse (Vaughn \& Leff, 1976; Hooley, Orley \& Teasdale, 1986). While some of the criticism centres on the depressed person's current symptomatic behaviour, a considerable portion is aimed at traits and behaviour evident before the onset of depression (Leff \& Vaughn, 1985).

\section{Marital Functioning}

Not surprisingly, the marital relationships of depressed persons are disrupted and may affect the severity of depression (Birtchnell \& Kennard, 1983). As many as seventy percent of depressed persons describe their marriage as poor before and after the onset of depression (Roy, 1987). Depression is more likely to be associated with marital problems when the depressed person is female. Among women, those with marital problems have poorer outcomes and they are likely to have continued marital problems at long-term follow-up (Rounsaville et al., 1979, 1980). Whereas depressed persons complain about the quality of the marital relationship, their spouses focus on the depression (Coyne, 1990).

Depressed persons and their spouses may have preexisting difficulties in the areas of intimacy, impulsivity and the handling of anger. Both demonstrate destructive styles in dealing with conflict (Coyne, 1990). Depression is apparently not incompatible with the expression of overt hostility, and depressed persons and their spouses express considerable hostility toward each other (Arkowitz et al. , 1982; Kahn et al., 1985).

Spouses' involvement in provoking and perpetuating depressed persons' difficulties is often ignored. For instance, depressed persons' complaints of insecurity and lack in self-confidence may reflect their involvement in marriages in which their spouses are unsupportive and critical (Leff \& Vaughn, 1985). Brown et al. (1986) assessed the spouses of depressed women who lacked an intimate relationship and found these spouses to be "grossly undependable" as partners and providers. Thus, depressed women's complaints about their spouses should not be dismissed as a distortion. The onset of a depressive episode following a severe life event is more likely when an intimate relationship with the spouse is lacking (Brown \& Harris, 1978). Even in the absence of a life event, onset of depression is also more likely when a person lacks intimate relationships (See Oatley \& Bolton, 1985, for review).

The spouses of depressed persons appear to have difficulties of their own which often predate the marriage (Merikangas, 1984). Depressed women from clinical and community samples are more likely than other women to be married to men with personal and family histories of depression, substance abuse and personality disorders (Merikangas \& Spiker, 1982; Negri et al., 1979; Peterson, Coyne \& Kessler, 1990). Evidence suggests that this is due to assortative mating: the diagnosable problems of both depressed persons and their spouses tend to have emerged before they were married (Peterson et al., 1990). There are also similarities between depressed persons and their spouses in terms of adverse childhood experiences and deviance as adolescents, and these shared background characteristics may be a key predictor of how destructive a depressed person and their spouse become when dealing with conflict (Coyne 1990), and, in turn, of the risk for a disturbed family climate and subsequent relapse.

\section{Depression and Parenting}

Children of depressed parents show a full range of difficulties including psychological, academic and even physical problems, including potential markers for future depression (See Downey \& Coyne, 1990, for a comprehensive review). Difficulties are apparent during infancy (Sameroff et al., 1982), early childhood (Seifer et al., 1981), primary school years (Neal \& Weintraub, 1975) and adolescence (Hirsch et al., 1985). 
One often-reached conclusion is that the problems experienced by the children of depressed parents are the result of pathogenic parenting behaviour, especially by depressed mothers. Yet examination of the evidence suggests a considerably more complex process linking depression in parents and a child's difficulties. As described in the literature, depressed parents experience difficulties in the parenting role one would anticipate from their symptoms. A depressed parent's low energy (Cohn et al., 1990) and feelings of helplessness and hostility (Weissman \& Paykel, 1974) limit their ability to meet or even acknowledge the child's needs (Fisher, Kokes, Harder \& Jones, 1980). Difficulty being decisive and low selfconfidence appear to lead to inconsistent parenting and discipline (Susman et al., 1985); harsh punishments and strict rules alternate with a laissez faire or permissive approach (Drake \& Price, 1975). However, the serious stressors precipitating depression in a parent and the marital problems that are associated with it may have direct effects on both parenting and the well-being of children. These difficulties remain alternative explanations for the documented difficulties of the children of depressed parents.

The risk for disturbance in the children with one depressed parent increases if the other parent is also disturbed (Kuyler et al., 1980; Weissman et al., 1984). Yet the risk to children of depressed parents is largely eliminated if the other parent is well adjusted, supportive and available to the child (Downey \& Coyne, 1990). One key, but under-utilised, argument for a greater involvement of family therapists in the treatment of depression is that they are in a unique position to work with the whole family to reduce the risk to the children of depressed parents.

\section{CONCLUSION}

Family therapists need to be prepared to specify how changes in family functioning might benefit depressed persons and to identify the other problems in these families and their unmet needs for treatment. At the same time, family therapists should be alert to undetected depression in the adults and children in families referred to them for other reasons. Most diagnosable depression goes undetected and untreated, and yet it has important implications for the functioning of depressed persons and their families. Resolution of family conflicts, re-establishment of routines, and maintenance of consistency in parenting, are all considerably more difficult when depression in an adult or child is not addressed.

Treating depressed persons and their families requires flexibility and humility. No one approach appears to work consistently, and therapists should be prepared to reevaluate the appropriateness of their efforts when these do not appear to be working with a particular family or couple. Furthermore, a decision to seek consultation or referral for medication should not be construed as a failure on the part of the therapist, the depressed person, or the family. Therapists need to come to terms with the overwhelming evidence that antidepressant medication provides effective treatment for many depressed persons. At the same time, they should be prepared to advance the case for marital and family therapy, be able to point to what it might accomplish that medication will not, and seek collaboration with other professionals when it is in the best interest of depressed persons and their families. It is important to identify physicians who respect the contribution of marital and family therapy and who are prepared to engage in such collaboration.

The array of difficulties presented by the families of depressed persons can prove daunting. Family therapists should be careful not to replicate the family members' tendencies to personalise these difficulties or succumb to the families' demoralisation, particularly in the face of inevitable setbacks. These families may have longstanding and seemingly intractable difficulties, but these should not distract the therapists from their strengths and the changes which are nonetheless within reach. It is important to keep a clear, even if flexible, set of goals in mind, and not to lose sight of the diverse reasons why family members are willing to participate in therapy, and what would allow them to get on with their lives without the need for further therapy.

\section{References}

Arkowitz, H., Holliday, S. and Hutter, M., 1982. Depressed women and their husbands: A study of marital interaction and adjustment. Paper presented at the Annual Meeting of the Association for the Advancement of Behavior Therapy, November.

Beach, S.R.H., Sandeen, E.E. and O'Leary, K.D., 1990. Depression in Marriage, New York, Guilford.

Beckman, E.E. and Leber, W.R., 1985. The comparative efficacy of psychotherapy and pharmacotherapy. In E.E. Beckman and W.R. Leber (Eds.), Handbook of Depression. Homewood, Ill., Dorsey Press.

Bender, K.J., 1990. Psychiatric Medications. A Guide for Mental Health Professionals, Newbury Park, CA., Sage Publications.

Birtchnell, J. and Kennard, J., 1983. Does marital maladjustment lead to mental illness?, Social Psychiatry, 18: 79-88.

Blackburn, I.M., Bishop, S., Glen, A.I.M., Whalley, L.J. and Christie, J.C., 1981. The efficacy of cognitive therapy in depression: A treatment trial using cognitive therapy and pharmacotherapy, each alone and in combination, Br. J. of Psychiatry, 139: 181-89.

Brown, G.W., Bifulco, A., Harris, T. and Bridge, L., 1986. Life stress, chronic subclinical symptoms and vulnerability to clinical depression, J. Affective Disorders, 11: 1-19.

Brown, G.W. and Harris, T., 1978. Social origins of depression: $A$ study of psychiatric disorder in women, New York, Raven Press.

Clarkin, J.F., Glick, I.D., Haas, G.L. and Spencer, J.H., 1990. A randomised clinical trial of inpatient family intervention: V. Results for affective disorders, Journal of Affective Disorders, 18: 17-28.

Clayton, P.J. and Barrett, J.E. (Eds.), 1983. Treatment of depression: Old controversies and new approaches, New York, Raven Press.

Cohn, J.F., Campbell, S.B., Matias, R. and Hopkins, J., 1990. Faceto-face interactions of postpartum depressed and nondepressed mother-infant pairs at 2 months, Developmental Psychology, 26: 15-23.

Coyne, J.C., 1991. Depression and marital problems. Paper presented at the Annual Meeting of Association for the Advancement of Behavior Therapy, New York, November.

Coyne, J.C., 1991. Review of Beach, Sandeen, and O'Leary, Depression in marriage, J. Marital and Fam. Therapy, 17: 414-15.

Coyne, J.C., Burchill, S.A.L. and Stiles, W.B., 1991. An interactional perspective on depression. In C.R. Snyder and D.O. Forsyth (Eds.), Handbook of Social and Clinical Psychology: The Health Perspective, New York, Pergamon.

Coyne, J.C., Kessler, R.C., Tal, M., Turbull, J., Wortman, C. and Greden, J., 1987. Living with a depressed person: Burden and psychological distress, J. Consulting and Clinical Psychology, 55: 347-52. 
Crowther, J.H., 1985. The relationship between depression and marital maladjustment: A descriptive study, J. Nerv. Mental Dis., 173: 227-31.

Dolan, R.J., Calloway, S.P., Fonagy, P., De Souza, F.V.A. and Wakeling D., 1985. Life events, depression, and hypothalamicpituitary-adrenal axis function, Br. J. Psychiatry, 147: 429-33.

Downey, G. and Coyne, J.C., 1990. Children of depressed parents: An integrative review, Psychological Bulletin, 108: 50-76.

Drake, R.E. and Price J.L., 1975. Depression: adaptation to disruption and loss, Perspect. Psychiat. Care, 13: 163-69.

Elkin, I., Shea, M.T., Watkins, J.T. and Eimber, S.D., 1989. National Institute of Mental Health treatment of depression collaborative research program, Arch. Gen. Psychiatry, 46: 971-82.

Fisher, L., Kokes, R.F., Harder, D.W. and Jones, J.E., 1980. Child competence and psychiatric risk: VI Summary and integration of findings, J. Nervous and Mental Disease, 168: 353-55.

Foley, S.H., Rounsaville, B.J., Weissman, M.M., Scholomskas, D. and Chevron. E., 1989. Individual versus conjoint interpersonal psychotherapy for depressed patients with marital disputes, International J. of Fam. Psychiatry, 10: 29-42.

Fowles, D.C. and Gershon, F.S., 1979. Neurotic depression: The endogenous-reactive distinction. In R.A. Depue (Ed.), The psychobiology of depressive disorders, New York, Academic Press.

Friedman, A.S., 1975. Interaction of drug therapy with marital therapy in depressive patients, Arch. Gen. Psychiatry, 32: 619-37.

George, L.K., Blazer, D.G., Hughes, D.C. and Fowler, N., 1989. Social outcome and the outcome of major depression, Brit. J. of Psychology, 32: 478-85.

Glick, I.D., Burti, L., Minakawa, K., Machara, K. and Sacks, M., 1991. Effectiveness in psychiatric care II. Outcome for the family after hospital treatment for major affective disorder, Ann. of Clin. Psychiatry, 3: 187-98.

Hinchliffe, M., Hooper, D., Roberts, F.J. and Vaughn, P.W., 1975. A study of the interaction between depressed patients and their spouses, Br. J. Psychiatry, 126: 164-72.

Hirsch, B.J., Moos, R.R. and Reischl, T.M., 1985. Psychosocial adjustment of adolescent children of a depressed, arthritic, or normal parent, J. of Abnormal Psychology, 94: 154-64.

Hooley, J.M., Orley, J. and Teasdale, J.D., 1986. Levels of expressed emotion and relapse in depressed patients, Br. J. Psychiatry, 148: 642-47.

Hooley, J.M. and Teasdale, J.D., 1989. Predictors of relapse in unipolar depressives: Expressed emotion, marital distress and perceived criticism, J. Abnorm. Psychol., 98: 229-35.

Hops, H., Biglan, A., Sherman, L., Arthur, J., Friedman, L. and Osteen, R., 1987. Home observations of family interactions of depressed women, J. Consult. Clin. Psychol., 55: 341-46.

Jacobson, N.S., Dobson, K., Fruzzeti, A.E., Schmaling, D.B. and Salusky, S., 1991. Marital therapy as a treatment for depression, J. Consult. Clin. Psychology, 57: 5-10.

Kahn, J., Coyne, J.C. and Margolin, G., 1985. Depression and marital conflict: The social construction of despair, J. Soc and Personal Relationships, 2: 447-62.

Keitner, G.I. and Miller I.W., 1990. Family functioning and major depression: An overview, Am. J. Psychiatry, 147: 1128-37.

Keller, M.B., Klerman, G.L., Lavori, P.W., Curyell, W., Endicott, J. and Taylor, J., 1984. Long term outcome of episodes of major depression: Clinical and public health significance, JAMA, 252: 788-92.

Keller, M.B. and Shapiro, R.W., 1982. Double depression: Superimposition of acute depressive episodes on chronic depressive disorders, Am. J. Psychiatry, 139: 438-42.

Kendler, K.S., Neale, M.C., Kessler, R.C., Heath, A.C. and Eaves, L.J., 1992. A population based twin study of major depression in women, Archives Gen. Psychiatry, 49: 257-266.

Kuyler, P.L., Rosenthal, L., Ingel, D., Dunner, D.L. and Fieve, R.R., 1980. Psychopathology among children of manic depressive patients, Biological Psychiatry, 15: 589-97.

Leff, J. and Vaughn, C.E., 1985. Expressed emotion in families: Its significance for mental illness, New York, Guilford.

Markowitz L., 1991. Better therapy through chemistry, The Family Networker, 15: 22-33.
McGuffin, P., Katz, R. and Rutherford, J., 1991. Nature, nurture and depression: A twin study, Psychological Med., 21: 329-335.

Merikangas, K.R. and Spiker, D.G., 1982. Assortative mating among in-patients with primary affective disorder, Psychological Medicine, 12: 753-64.

Merikangas, K.R., 1984. Divorce and assortative mating among depressed patients, Am. J. Psychiatry, 141: 74-6.

Miklowitz, D.J. and Goldstein, M.J., 1990. Behavioral family treatment for patients with bipolar affective disorder, Behavior Modification, 14: 457-489.

Miller, I.W., Kabacoff, R.I., Keitner, G.I. and Epstein, N., 1986. Family functioning in the families of psychiatric patients, Compr. Psychiatry, 27: 302-12.

Morgan, R., 1988. The Emotional Pharmacy: How Mood-Altering and Psychoactive Drugs Work, Los Angeles, CA, The Body Press.

Murphy, G.E., Simons, A.D., Wetzel, R.D. and Lustman, P.J., 1984. Cognitive therapy and pharmacotherapy, Arch. Gen. Psychiatry, 41: $22-41$.

Neale, J.M. and Weintraub, S., 1975. Children vulnerable to psychopathology: The Stony Brook High-Risk Project, J. Abnormal Child Psychology, 3: 96-113.

Negri, F., Melica, A.M., Zuliani, R. and Smeraldi, E., 1979. Assortative mating and affective disorders, J. Affect. Disord., 1: 247-53.

Oatley, K. and Bolton, W., 1985. A social-cognitive theory of depression in reaction to life events; Psychol. Rev., 3: 374-88.

O'Leary, K.D. and Beach, S.R.H., 1990. Marital therapy: A viable treatment for depression and marital discord, Am. J. Psychiatry, 147: 183-186.

Peterson, P., Coyne, J.C. and Kessler, R.C., 1990. Assortative mating in a community sample. Unpublished manuscript, University of Michigan.

Rounsaville, B.J., Prusoff, B.A. and Weissman, M.M., 1980. The course of marital disputes in depressed women: A 48-month follow-up study, Compr. Psychiatry, 21: 111-18.

Rounsaville, B.J., Weissman, M.M., Prusoff B.A. and Herceg-Baron R.L., 1979. Marital disputes and treatment outcome in depressed women, Compr. Psychiatry, 20: 483-90.

Rounsaville, B.J., Klerman, G.I. and Weissman, M.M., 1981. Do psychotherapy and pharmacotherapy for depression conflict? Empirical evidence from a clinical trial, Archives General Psychiatry, 38: 24-29.

Roy, A., 1987. Five risk factors for depression, Br. J. Psychiatry, 150: 536-41.

Sameroff, A.J., Seifer, R. and Zax M., 1982. Early development of children at risk for emotional disorder, Monographs of the Society for Research in Child Development, 47(7, Serial No. 199).

Seifer, R., Sameroff, A.J. and Jones, F., 1981. Adaptive behavior in young children of emotionally disturbed women, J. Developmental Psychol, 1: 251-76.

Susman, E.J., Trickett, P.K., Jannotti, R.J., Hollenbeck, B.E. and Zahn-Waxler, C., 1985. Child-rearing patterns in depressed, abusive, and normal mothers, Am. J. Orthopsychiatry, 55: 237-51.

Thase, M.E., Himmelhock, J.M., Hersen, M. and Bellack, A.S., 1984 Poor response to psychotherapies in melancholia. Paper presented at the meeting of the American Psychiatric Association, Los Angeles, CA.

van Praag, H.M., 1982. A transatlantic view of the diagnosis of depression according to DSM-III: I. Controversies and misunderstandings in the depression diagnosis, Comprehensive Psychiatry, 129: 125-37.

Vaughn, C.E. and Leff, J.P., 1976. The influence of family and social factors on the course of psychiatric illness, Br. J. Psychiatry, 129: 125-37.

Weissman, M. and Paykel, E., 1974. The depressed woman: A study of her relationships, Chicago, Ill., University of Chicago Press.

Weissman, M.M., Prussoff, B.A., Gammon, G.D., et al., 1984. Psychopathology in children (ages 6-18) of depressed and normal parents, J. Am. Acad. Child Psychiatry, 23: 78-84.

Wells, K.B., Stewart, A., Hays, R.D., Burman, M.A., Rogers, W., Daniels, M., Berry, S., Greenfields, S. and Ware, J., 1989. The functioning and well-being of depressed patients. Results from the Medical Outcomes Study, JAMA, 262: 914-19. 